\title{
ORNL Trusted \\ Corridors Project: Watts Bar Dam Inland Waterway Project Lessons Learned
}

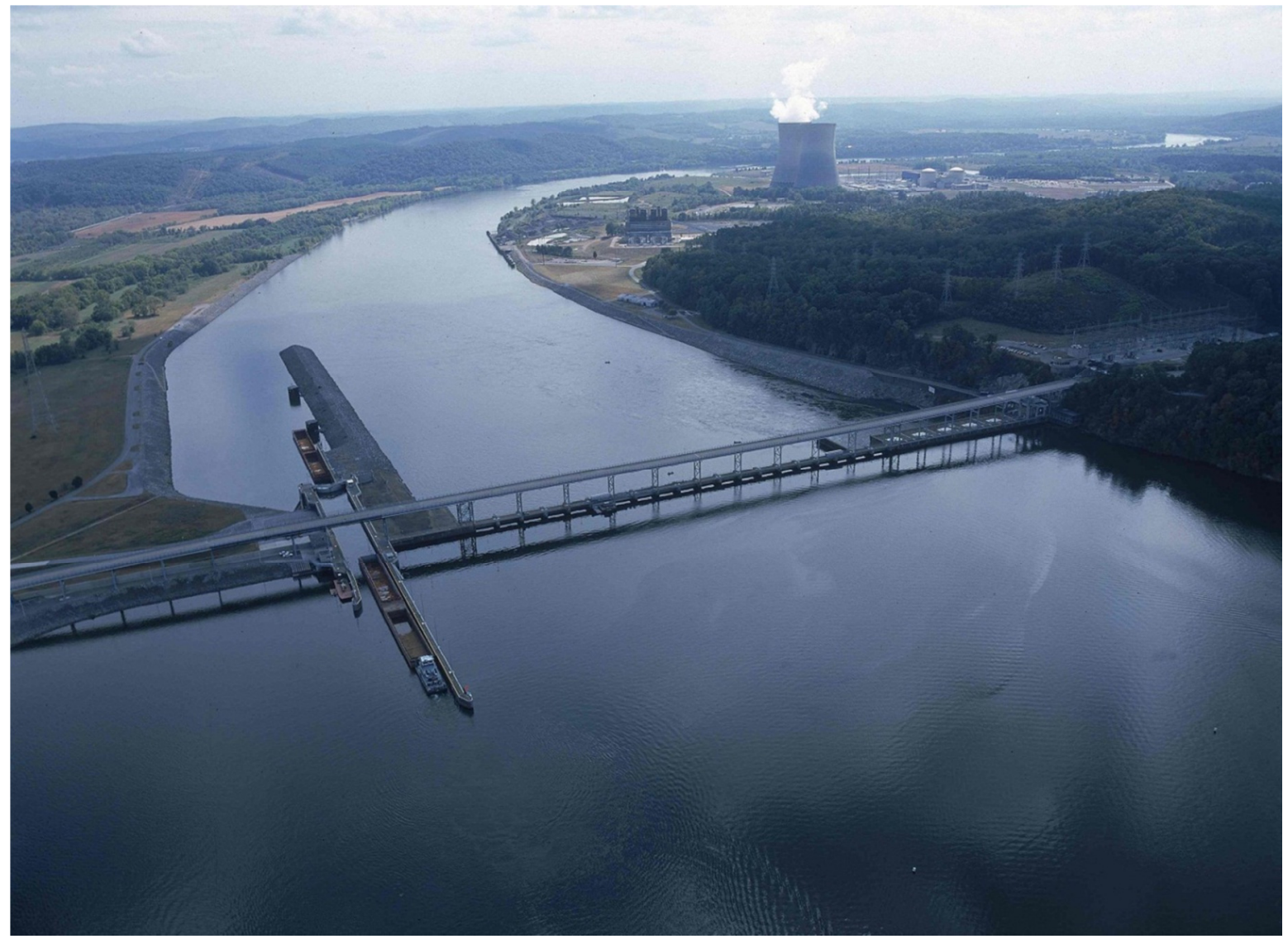

Randy Walker

Ian Gross

Cy Smith

David Hill

POC walkerrm1@ornl.gov

\section{Oak Ridge National Laboratory}

1

This document was prepared by Oak Ridge National Laboratory, PO Box 2008, Oak Ridge, Tennessee 37831-6285, managed by UT-Battelle, LLC, for the US Department of Energy under contract DE-AC05-00OR22725. 


\section{Background}

Installation of the radiation bulk monitoring sensors at the Tennessee Valley Authority's (TVA) Watts Bar Dam was an extension of the Oak Ridge National Laboratory (ORNL) Trusted Corridors Project under the Office of Naval Research funded SensorNet program. The Trusted Corridors Project began in 2002 with the placement of radiation detectors at weigh and inspection stations along Interstate 40 near Knoxville, TN and Interstate 26 in Dorchester County South Carolina. The Trusted Corridor deployments in Tennessee and South Carolina were unique in that they were the first of their kind to be installed at weigh stations and waterway locks under the auspices of State safety and law enforcement organizations. ${ }^{\mathrm{i}}$

The Watts Bar Dam Inland Waterway Project was a collaborative effort between Oak Ridge National Laboratory (ORNL), TVA, and the Army Corps of Engineers (ACE). In 2004, ORNL installed with assistance from TVA and ACE four Exploranium AT 900 Polyvinyl Toluene Plastic Scintillator (PVT) panels in the lock doors of the TVA Watts Bar Dam in Meigs County, TN. At its inception the project received significant national and international attention both from a scientific and media standpoint. Early work was focused on procedure and protocol development and sensor integration and calibration.

Procedure and protocol development included input and support from the Department of Energy (DOE), Assistant United States Attorney's Office (AUSA), Federal Bureau of Investigation (FBI), US Coast Guard (USCG), TVA Police, the Tennessee Office of Homeland Security, Tennessee Wildlife Resource Agency (TWRA), and the Meigs and Rhea County Sheriff's Offices. The procedures and protocols were being developed with intent to perform live exercises including active participation from the partnering Federal, State and Local law enforcement agencies. Sensor calibration, development and integration progressed with key private sector sensor developers and ORNL working on the issues of background settings, algorithm development, technical reachback and Concept of Operations.

2

This document was prepared by Oak Ridge National Laboratory, PO Box 2008, Oak Ridge, Tennessee 37831-6285, managed by UT-Battelle, LLC, for the US Department of Energy under contract DE-AC05-00OR22725. 


\section{Purpose}

Radiation has existed everywhere in the environment since the Earth's formation - in rocks, soil, water, and plants. The mining and processing of naturally occurring radioactive materials for use in medicine, power generation, consumer products, and industry inevitably generate emissions and waste. Radiological measuring devices have been used by industry for years to measure for radiation in undesired locations or simply identify radioactive materials. Since the terrorist attacks on the United States on 9-11-01 these radiation measuring devices have proliferated in many places in our nation's commerce system. DOE, TVA, the Army Corps and ORNL collaborated to test the usefulness of these devices in our nation's waterway system on this project.

The purpose of the Watts Bar Dam ORNL Trusted Corridors project was to investigate the security, safety and enforcement needs of local, state and federal government entities for stateof-the-art sensor monitoring in regards to illegal cargo including utilization of the existing infrastructure. TVA's inland waterways lock system is a recognized and accepted infrastructure by the commercial carrier industry. Safety Monitoring activities included tow boat operators, commercial barges and vessels, recreational watercraft and their cargo, identification of unsafe vessels and carriers, and, monitoring of domestic and foreign commercial vessels and cargo identification. Safety Enforcement activities included cargo safety, tracking, identification of hazardous materials, waterway safety regulations, and hazardous materials regulations. Homeland Security and LawlEnforcement Applications included Radiological Dispersive Devices (RDD) identification, identification of unsafe or illicit transport of hazardous materials including chemicals and radiological materials, and screening for shipments of illicit drugs

3 This document was prepared by Oak Ridge National Laboratory, PO Box 2008, Oak Ridge, Tennessee 37831-6285, managed by UT-Battelle, LLC, for the US Department of Energy under contract DE-AC05-00OR22725. 

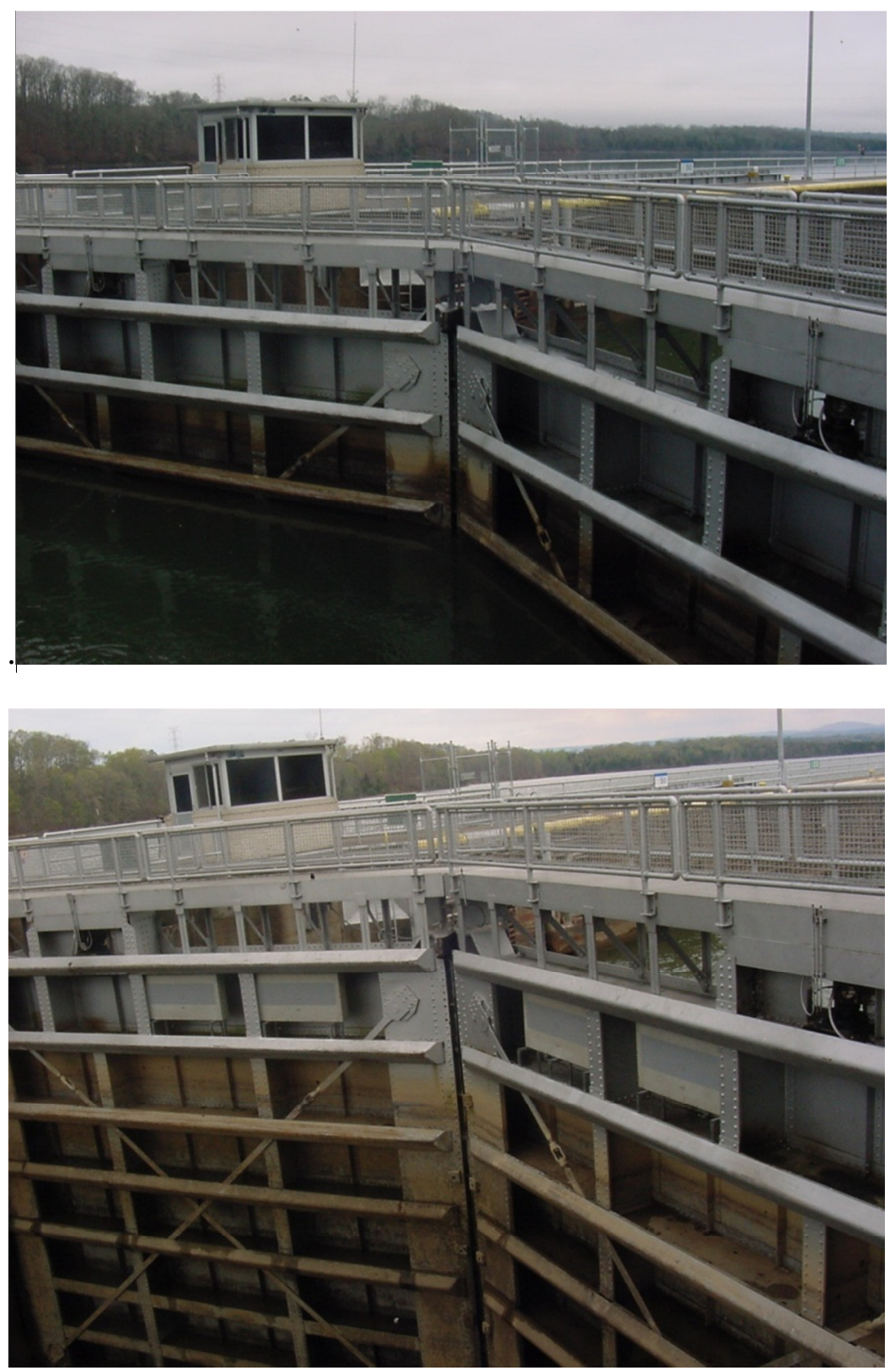

Before and after pictures of the Watts Bar Dam Lock Doors. The Bottom Picture shows the PVT Detectors in the Lock Doors 


\section{Watts Bar Project Plan}

The project goals were divided into five overarching categories as follows:

- Concept of Operations,

- Knowledge discovery,

- Procedures and Protocols,

- Human resource Optimization and Training, and

- Communications

Further projected subdivision of the project research goals are outlined below.

\section{Key Components Needed for Mission Success}

\begin{tabular}{|c|c|c|c|c|c|}
\hline & $\begin{array}{l}\text { Knowledge } \\
\text { Discovery }\end{array}$ & $\begin{array}{l}\text { Procedures } \\
\text { Protocols } \\
\text { and Policy }\end{array}$ & $\begin{array}{l}\text { Con Ops } \\
\text { Development } \\
\text { Applications }\end{array}$ & $\begin{array}{c}\text { Human Resource } \\
\text { Optimization and } \\
\text { Training }\end{array}$ & Communications \\
\hline $\begin{array}{l}\text { Bed Tesing } \\
\text { Toosy }\end{array}$ & 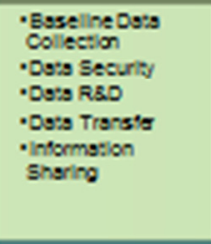 & 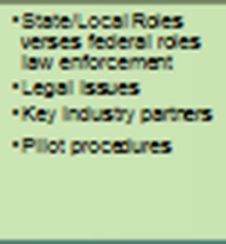 & 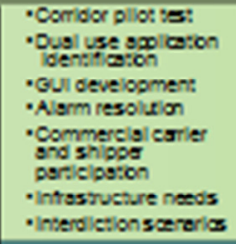 & 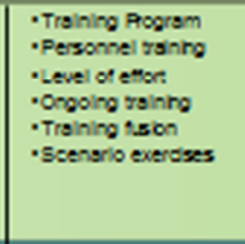 & 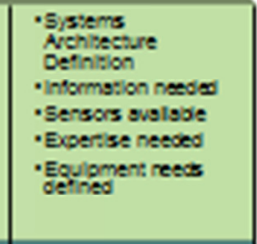 \\
\hline Nosongl bes: & 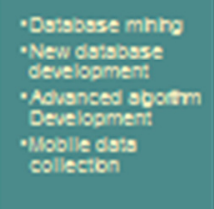 & 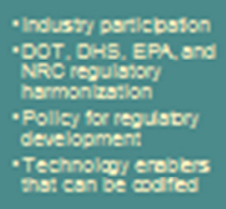 & 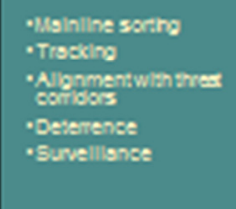 & 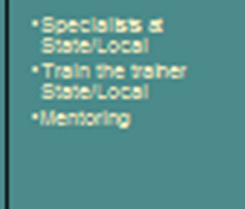 & 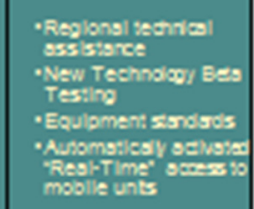 \\
\hline Goal & $\begin{array}{l}\text {-Nasiongl } \\
\text { Ausomgted/ } \\
\text { integrated Low } \\
\text { Entorgement. } \\
\text { Edistem } \\
\text { Ee on the Loovout }\end{array}$ & $\begin{array}{l}\text { - Hormonized } \\
\text { procedures sro } \\
\text { sandoros atFeders! } \\
\text { State, and Locs evel }\end{array}$ & 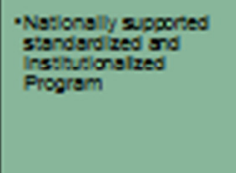 & 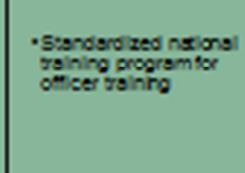 & 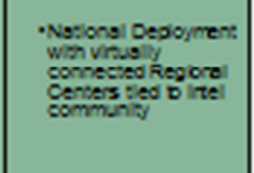 \\
\hline
\end{tabular}

The project was then divided into three phases as follows:

1. Field Testing,

2. Advance algorithm development data acquisition, and, data management, and

3. Broad based deployment strategy.

5

This document was prepared by Oak Ridge National Laboratory, PO Box 2008, Oak Ridge, Tennessee 37831-6285, managed by UT-Battelle, LLC, for the US Department of Energy under contract DE-AC05-00OR22725. 
The criteria for Phase I included:

- Assemble stakeholder team and develop procedures and protocol

- Use DOE supplied Exploranium PVT 900 bulk radiological monitoring system, digital camera and video technology, alarm notification sensors modified for barge and watercraft traffic

- Mounting of the system on the lock doors at Watts Bar Dam including meeting all safety and environmental requirements

- Conduct system testing and background measurements (See Appendix A)

- Utilize a Survey Form (see Appendix B) to obtain information from private watercraft.

- Alert local news media so public would be aware of testing

- Collect manifest data, weather data and digital photographs of barge and vessel traffic transferring though the lock.

- Collect data and document results using the ORNL SensorNet backbone including ongoing work to establish automated data collection.

- Establish security notification protocol in the event of an unusual occurrence or inexplicable anomaly.

- Data analysis and incorporate Lessons Learned into Phase II tests.

Phase I of the project commenced in the Spring of 2004 under the direction and funding of the SensorNet program and DOE-EM. The DOE-EM portion of the project sought to obtain the following information from the testing:

Under normal waterway operating conditions including varied environmental conditions, varied commodities on board barge, private watercraft and normal transportation handling.

Susceptibility and limitations of the technologies under varied environmental conditions;

Determine validity of bulk monitors for identification of NORM and TENORM materials in water transport.

\section{Findings}

1. The ORNL Project Team was aware that the Exploranium PVT sensors were limited in terms of detection of shielded cargo barge and vessel traffic, but the sensors were successful at identifying test sources placed on Army Corps boats passing through the locks and were readily available to the team as they were provided at no charge by DOE.

2. Elaborate algorithms were required to compensate for the rapid background changes associated with the dynamic environment at an operational dam/lock. Water level

6

This document was prepared by Oak Ridge National Laboratory, PO Box 2008, Oak Ridge, Tennessee 37831-6285, managed by UT-Battelle, LLC, for the US Department of Energy under contract DE-ACO5-00OR22725. 
changes by 40'; opening/closing of the locks (detectors 20' from concrete closed; 2 ' when open), barometric changes, high humidity (nearly 100\%), and dramatic temperature changes caused by shadowing, reflected sunlight, and a massive steel \& concrete heat sync created by the dam all required compensation to prevent false-positive alerts.

3. The ORNL Project Team was successful at calibrating the sensors in a heavy background radiation environment (i.e. naturally occurring radioactive material (NORM) from concrete), however the raising and lowering of water levels in the locking process did create calibration issues that had to be accounted for in the ConOps procedures.

4. Because the Watts Bar Dam lock is on a navigable river pleasure boats and private citizens were subject to inspection, this fact created some legal issues in the inspection process especially during a $\mathrm{R} \& \mathrm{D}$ pilot.

5. Law enforcement search and seizure jurisdiction and interdiction at the Watts Bar Lock was a shared responsibility between the Meigs and Rhea County Sheriffs and Attorney Generals, TVA Police, the USCG, the TWRA, the AUSA and the FBI. Specific responsibility for this project was deliberated (perhaps for the first time) by Federal, state and local law enforcement personnel. TWRA was determined to be the agency with the broadest powers for search and seizure of private watercraft. The US Coast Guard had regulatory responsibilities for commercial watercraft.

6. Technical reachback became a procedure and protocol issue with two types needed (i.e. system diagnostics and alarm resolution) for the R\&D project. At the time of the project there was no formal national technical reachback protocol.

7. Personnel training on equipment use, radioactive materials, US and State hazardous materials regulations, threat recognition all were needed and initially performed by the ORNL project team.

8. A graphical user interface (GUI) was developed that combines the Radiation sensors, cameras and alarming system. This GUI was unique to waterway traffic.

9. Data collection and mining were identified as critical to future deployments since there was no comparison data associated with radioactive materials either NORM or TENORM on the waterways.

7

This document was prepared by Oak Ridge National Laboratory, PO Box 2008, Oak Ridge, Tennessee 37831-6285, managed by UT-Battelle, LLC, for the US Department of Energy under contract DE-AC05-00OR22725. 
10. TVA was successful at performing engineering analysis that allowed the detectors to be mounted on the lock doors as well as obtaining a categorical exclusion from the National Environmental Protection Act requirements.

11. These types of pilot projects attract both national and local media attention creating a need for a press liaison and media plan.

12. Data transfer from Dam lock facilities requires significant band width that is not always available at these facilities.

\section{Summary}

In the Fall of 2005 the SensorNet funding for the project expired. After several unsuccessful attempts to find a Federal sponsor to continue with the project, the Watts Bar Dam Project was canceled and the Exploranium radiation monitors were removed from the doors of Watts Bar Dam in early 2006. The DHS Domestic Nuclear Detection Office decided to proceed with a Pilot building on the ORNL work performed at the TN and SC weigh stations in the highway sector of the Trusted Corridors project and eventually expanded it to other southern states under the name of Southeastern Corridor Pilot Project (SETCP). Many of the Phase I goals were achieved however real-world test data of private watercraft and barges was never obtained.

\section{Appendix A: Background Radiation Survey Information}

8

This document was prepared by Oak Ridge National Laboratory, PO Box 2008, Oak Ridge, Tennessee 37831-6285, managed by UT-Battelle, LLC, for the US Department of Energy under contract DE-AC05-00OR22725. 
Watts Bar Dam On East Lock (Open)

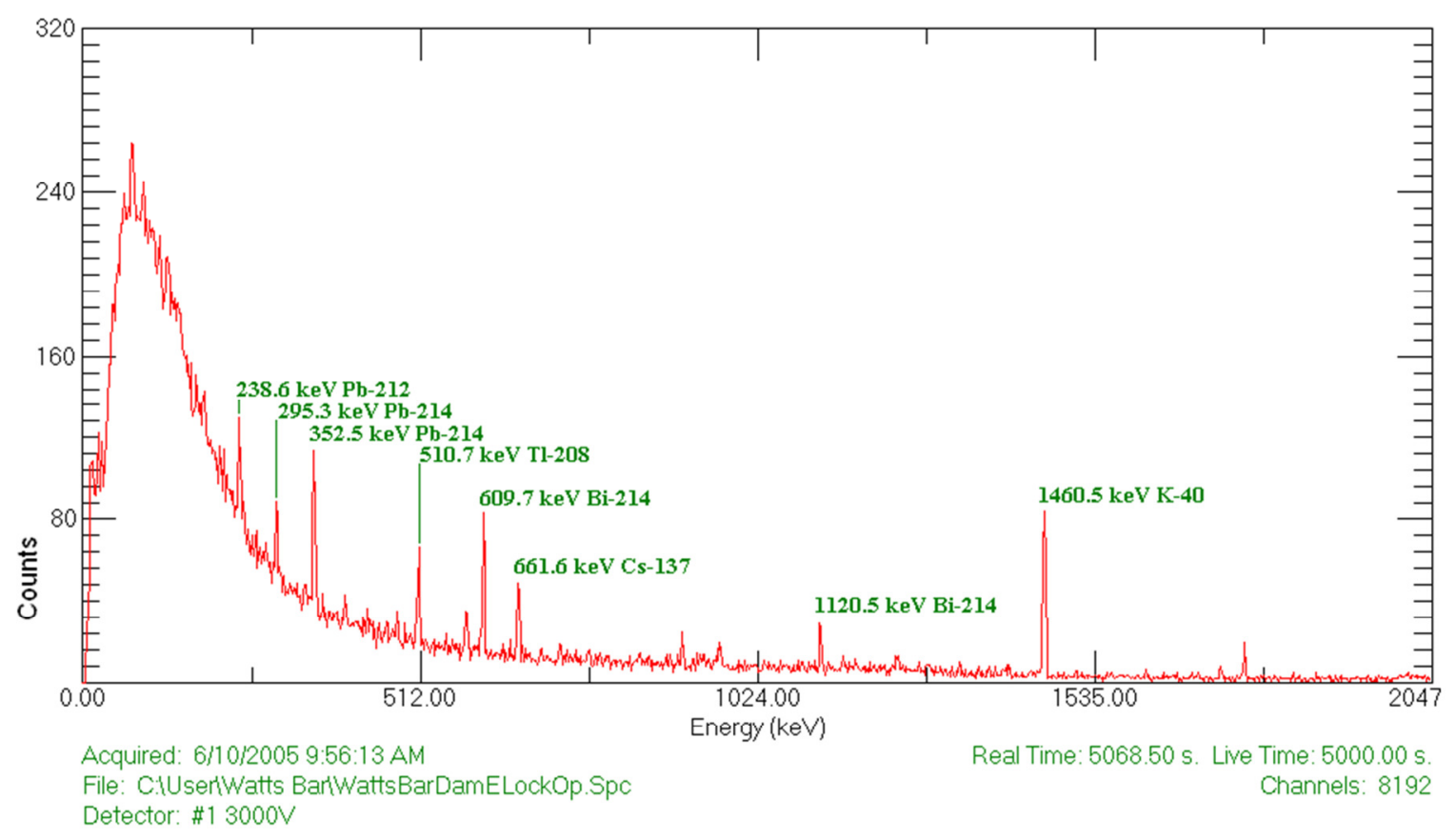

Analysis of Watts Barr Lock

June 7, 2005

The center of the lock and the east wall of the lock were analyzed with a high-purity germanium detector. A later count was done in a position and geometry much closer to that of the detectors of the study.

The count was not long enough for a good statistical analysis of the results. In the geometry used for the last scan a count time of six hours would be needed for good statistical results.

However, the radioisotopes present in the analysis were positively identified.

$\mathrm{U}-238$ was determined to be present from the detection of $\mathrm{Pb}-214$ and $\mathrm{Bi}-214$.

Th-232 was determined to be present from the detection of Ac-228, Pb-212, Bi-212, and Tl-208.

The results from the count are as follows:

Th-232 $\quad 5.4 \%$

U-238 $\quad 6.1 \%$

Cs-137 2.2\% (A Cs-137 check source was near the detector during the count)

K-40 $86.3 \%$

Appendix B: Watts Bar Dam User Survey Form

\section{ORNL SURVEY FOR WATERWAY TRANSPORT}

9

This document was prepared by Oak Ridge National Laboratory, PO Box 2008, Oak Ridge, Tennessee 37831-6285, managed by UT-Battelle, LLC, for the US Department of Energy under contract DE-AC05-000R22725. 
TO BETTER ENSURE SAFETY AND SECURITY ON OUR NATION'S WATERWAYS THE OAK RIDGE NATIONAL LABORATORY (ORNL) IN COOPERATION WITH THE ARMY CORPS OF ENGINEERS (ACE) AND THE TENNESSEE VALLEY AUTHORITY IS CONDUCTING A SURVEY OF WATERWAY USERS. PLEASE TAKE A FEW MINUTES WHILE YOU TRANSFER THROUGH THE LOCK TO ANSWER A FEW QUESTIONS FOR US. THIS SURVEY INFORMATION IS STRICTLY FOR THE USE OF ORNL IN RESEARCH AND DEVELOPMENT EFFORTS AND YOUR PARTICIPATION IS PURELY VOLUNTARY.

1. How often do you use the TVA lock system?
a. 1-5 times per year
b. 6-20 times per year
c. Over 20 times per year

2. Are you a Tennessee resident?
a. Yes
b. No

3. Please circle the materials that are currently on your boat?
a. Life Jackets
b. Lanterns
c. Propane
d. Smoke Detectors
e. Food and Beverage
f. Clothing
g. Live Plants
h. Pets

4. How many people are currently on your watercraft?
a. 1-2
b. 3-5
c. $6-8$
d. $9-10$

5. Has anyone on your watercraft recently (past month) had a medical procedure that involved one of the following? Please circle appropriate category. 

a. Radiation treatment
b. Root canal
c. X-ray
d. Chemotherapy
e. Eye dilation
f. Heart procedure involving medical dye
g. Sonogram

6. Did you trailer your boat to the lake today?
a. Yes
b. No

7. Which best describes your waterway usage? Circle all that apply.
a. Fishing
b. Recreational Boating
c. Sailing
d. Hunting
e. Water sports (tubing, skiing, etc.)
f. Transportation
g. Commercial activities
h. Attending an event (ballgame, festival, etc)

8. What is the length of your boat?
a. Jet ski
b. Under 18'
c. $18^{\prime}-25^{\prime}$
d. Over 25'

9. How many days will you spend on the lake this trip?
a. 1
b. 2
c. 3 or more

10. What type of boat are you using?
a. Personal Watercraft
b. Pontoon
c. Fixed Hull 
Thank you for filling out our survey. Please place the pen and form in the provided container and return to the Watts Bar Dam attendant.

'ORNL/TM-2006/519, Requirements Definition for ORNL Trusted Corridors Project, Walker R.M. et-al

12

This document was prepared by Oak Ridge National Laboratory, PO Box 2008, Oak Ridge, Tennessee 37831-6285, managed by UT-Battelle, LLC, for the US Department of Energy under contract DE-AC05-00OR22725. 